(C) Cambridge University Press 2009. The online version of this article is published within an Open Access

environment subject to the conditions of the Creative Commons Attribution-NonCommercial-ShareAlike

licence <http://creativecommons.org/licenses/by-nc-sa/2.5/>. The written permission of

Cambridge University Press must be obtained for commercial re-use.

\title{
Dissociation of long-term verbal memory and fronto-executive impairment in first-episode psychosis
}

\author{
V. C. Leeson ${ }^{1,2 *}$, T. W. Robbins ${ }^{3}$, C. Franklin ${ }^{2}$, M. Harrison ${ }^{2}$, I. Harrison ${ }^{2}$, M. A. Ron ${ }^{1}$, T. R. E. Barnes ${ }^{2}$ \\ and E. M. Joyce ${ }^{1}$ \\ ${ }^{1}$ Institute of Neurology, University College London, UK \\ ${ }^{2}$ Imperial College Faculty of Medicine, London, UK \\ ${ }^{3}$ Department of Experimental Psychology, University of Cambridge, UK
}

Background. Verbal memory is frequently and severely affected in schizophrenia and has been implicated as a mediator of poor clinical outcome. Whereas encoding deficits are well demonstrated, it is unclear whether retention is impaired. This distinction is important because accelerated forgetting implies impaired consolidation attributable to medial temporal lobe (MTL) dysfunction whereas impaired encoding and retrieval implicates involvement of prefrontal cortex.

Method. We assessed a group of healthy volunteers $(n=97)$ and pre-morbid IQ- and sex-matched first-episode psychosis patients $(n=97)$, the majority of whom developed schizophrenia. We compared performance of verbal learning and recall with measures of visuospatial working memory, planning and attentional set-shifting, and also current IQ.

Results. All measures of performance, including verbal memory retention, a memory savings score that accounted for learning impairments, were significantly impaired in the schizophrenia group. The difference between groups for delayed recall remained even after the influence of learning and recall was accounted for. Factor analyses showed that, in patients, all variables except verbal memory retention loaded on a single factor, whereas in controls verbal memory and fronto-executive measures were separable.

Conclusions. The results suggest that IQ, executive function and verbal learning deficits in schizophrenia may reflect a common abnormality of information processing in prefrontal cortex rather than specific impairments in different cognitive domains. Verbal memory retention impairments, however, may have a different aetiology.

Received 7 November 2008; Revised 3 March 2009; Accepted 18 March 2009; First published online 7 May 2009

Key words: First episode, psychosis, schizophrenia, verbal learning, verbal memory.

\section{Introduction}

Of all cognitive domains, verbal memory is one of the most frequently and severely affected in schizophrenia (Heinrichs \& Zachzanis, 1998; Aleman et al. 1999); the deficit is present at all stages of the illness (Saykin et al. 1994) and has been implicated as a mediator of poor clinical outcome (Green et al. 2000). However, the exact nature of the verbal memory deficit is still not established. Whereas there is little doubt that schizophrenia patients demonstrate encoding deficits, manifest as poor learning, it is still unclear whether retention of verbal material is impaired (see Cirillo \& Seidman, 2003). When delayed recall is corrected for initial

* Address for correspondence: Dr V. C. Leeson, UCL Institute of Neurology, Room 807 Queen Square House, 22 Queen Square,

London WC1N 3BG, UK.

(Email: v.leeson@ion.ucl.ac.uk) learning, some studies (Toulopoulou et al. 2003; Nuyen et al. 2005; Chan et al. 2006; Rametti et al. 2007) but not others (Holthausen et al. 2003; Kristian Hill et al. 2004; Lee et al. 2006; Roofeh et al. 2006) find an effect of delay on free recall. In those studies finding impaired delayed recall, it is unclear whether this represents a failure of retrieval of stored information or a failure of storage per se.

It is important to distinguish between the component processes contributing to memory impairment in schizophrenia because they are subserved by different neural processes and this has implications for understanding the neurobiology of the disorder. For example, impaired encoding and retrieval implicates involvement of prefrontal cortex (Fletcher \& Henson, 2001) whereas accelerated forgetting implies impaired consolidation attributable to medial temporal lobe (MTL) dysfunction (Alvarez \& Squire, 1994). 
Another reason for dissecting memory performance and its relationship to other forms of cognitive dysfunction is because of the controversy concerning the nature of cognitive impairment in schizophrenia. As most neuropsychological studies find wideranging impairments (e.g. Mohamed et al. 1999; Bilder et al. 2000), an important question is whether this represents multiple independent and possibly differential impairments of specific cognitive processes (Nuechterlein et al. 2004) or whether schizophrenia is best characterized by a generalized cognitive impairment varying from person to person in degree (Dickinson et al. 2004). In particular, under many circumstances, episodic encoding and retrieval entail cognitive control processes that affect the ability to plan, initiate strategies and inhibit distractions (Ranganath et al. 2008), and therefore it is important to determine whether memory deficits can occur independently of executive dysfunction in schizophrenia.

We have addressed these questions in large groups of healthy volunteers and first-episode psychosis patients. First, we investigated the various subcomponents of episodic memory. Second, we compared performance of verbal memory measures with measures of visuospatial executive function and general ability. Our hypothesis was that measures of episodic memory would be specifically and strongly associated with executive function performance, indicating the primacy of prefrontal cortex impairment in the neurobiology of schizophrenia.

\section{Method}

Subjects

Patients were recruited as part of a study of firstepisode psychosis in West London. Those eligible presented from the community to mental health services with a psychotic illness for the first time and had no more than 12 weeks cumulative exposure to antipsychotic medication. Data from 97 patients were included on the basis that they had received an initial diagnosis of schizophrenia, schizophreniform or schizo-affective disorder, completed all neuropsychological assessments and undertaken clinical assessments sufficient to make a final diagnosis. A follow-up clinical assessment was performed on all but 14 patients at least 1 year following first presentation. Of those patients who declined or were unavailable for reassessment, follow-up clinical information including diagnoses was obtained from clinical case-notes for 12 patients. The diagnoses for the remaining two patients were based on current clinical state and duration of illness. The final DSM-IV diagnoses were schizophrenia in 86 and schizo-affective disorder in 11. At the time of assessment, five were medication free, 15 were receiving first-generation antipsychotics, 75 second-generation antipsychotics and two a combination of both; 11 were taking anticholinergics.

Ninety-seven healthy volunteers served as controls, recruited by advertising in local job centres, schools and hospitals. Exclusion criteria were a personal history of psychiatric illness or a history of such illness in any first-degree relatives, previous head injury, neurological or endocrine disorder known to affect brain function, and drug or alcohol abuse. Table 1 contains demographic information on both groups.

The patient and control groups were taken from larger groups of 173 psychotic patients and 144 controls on the basis that they could be one-to-one matched on National Adult Reading Test (NART) pre-morbid IQ (68 were exactly the same, 25 were within one IQ point and four were within two IQ points) and sex. Age was also matched as closely as possible.

Permission to conduct the study was obtained from the relevant Research Ethics Committees. All participants gave written informed consent and were paid an honorarium for their time. A subset of the cognitive data from 31 patients and 17 controls has been reported previously (Joyce et al. 2005).

\section{Clinical assessments}

Psychotic symptoms were assessed with the Scales for the Assessment of Positive and Negative Symptoms (SAPS and SANS; Andreasen, 1983, 1984). Scores for the three symptom-derived syndromes of schizophrenia (Liddle \& Barnes, 1990) were calculated for each patient. Depression was assessed in 60 patients with the Hamilton Depression Rating Scale (HAMD; Hamilton, 1960). The dates of onset of psychosis were elicited as reported previously (Barnes et al. 2000) to calculate the duration of untreated psychosis (DUP). Pre-morbid function was assessed using the scales for Premorbid Social Adjustment (PSA) and Premorbid Schizotypal Traits (PSST) (Foerster et al. 1991).

\section{Neuropsychological assessments}

Cognitive assessments were performed when the patients were clinically stable as judged by the clinical team; this was within 1 week of the initial clinical assessment for $38 \%$ and 4 weeks for $78 \%$. The remainder were tested within 2 months except four patients tested at 11, 11, 23 and 24 weeks. Pre-morbid IQ was estimated using the Revised NART (Nelson \& Willison, 1991). Current IQ was calculated from four subtests of the Wechsler Adult Intelligence ScaleRevised (WAIS-R: 37 patients, 17 controls; Wechsler, 
Table 1. Demographic and cognitive profiles of the patient and control groups

\begin{tabular}{|c|c|c|c|c|}
\hline & \multirow[b]{2}{*}{ Healthy subjects } & \multirow[b]{2}{*}{ Patients } & \multicolumn{2}{|l|}{ Statistics } \\
\hline & & & $F(1,193)$ & $p$ \\
\hline$n$ & 97 & 97 & & \\
\hline Age at testing (years) & $26.17(7.14)$ & $26.68(6.19)$ & 0.27 & 0.61 \\
\hline Sex (male/female) & $61 / 36$ & $61 / 36$ & & \\
\hline NART pre-morbid IQ & $100.92(11.48)$ & $100.89(11.63)$ & 0.00 & 0.99 \\
\hline WAIS current IQ & $102.99(14.02)$ & $91.98(15.38)$ & 27.50 & $<0.001$ \\
\hline \multicolumn{5}{|l|}{ Verbal memory } \\
\hline Immediate recall & $6.15(1.86)$ & $5.58(1.76)$ & 4.77 & 0.03 \\
\hline Learning (sum a1-a5) & $49.97(9.46)$ & $43.02(9.37)$ & 26.48 & $<0.001$ \\
\hline Short-delay recall & $10.56(2.64)$ & $8.31(2.72)$ & 33.97 & $<0.001$ \\
\hline Long-delay recall & $10.09(2.96)$ & $7.43(2.85)$ & 40.66 & $<0.001$ \\
\hline Retention (\%) & $95.20(15.59)$ & $88.23(21.39)$ & 6.74 & 0.01 \\
\hline Delayed recognition (d prime) & $0.33(1.58)$ & $-0.33(1.50)$ & 8.77 & 0.003 \\
\hline Proactive interference & $0.61(2.21)$ & $0.65(1.87)$ & 0.02 & 0.89 \\
\hline Retroactive interference & $1.57(1.66)$ & $2.12(1.87)$ & 4.81 & 0.03 \\
\hline \multicolumn{5}{|l|}{ Executive functions } \\
\hline Working memory span & $6.51(1.38)$ & $5.40(1.33)$ & 32.23 & $<0.001$ \\
\hline Working memory manipulation (errors) & $17.46(15.84)$ & $33.41(18.82)$ & 40.78 & $<0.001$ \\
\hline Attentional set-shifting (EDS errors) & $9.15(8.86)$ & $13.32(10.38)$ & 9.03 & 0.003 \\
\hline Planning (perfect solutions) & $8.64(1.78)$ & $7.20(2.56)$ & 20.73 & $<0.001$ \\
\hline
\end{tabular}

Values given as mean (standard deviation).

NART, National Adult Reading Test; WAIS, Wechsler Adult Intelligence Scale; EDS, extra-dimensional shift.

1981) or the Wechsler Adult Intelligence Scale - Third Edition (WAIS-III; 60 patients, 80 controls; Wechsler, 1997), which have been shown to provide reliable measures of full-scale IQ in psychosis (Missar et al. 1994; Blyler et al. 2000). These subtests were information, arithmetic, block design and digit symbol from the WAIS-III and information, similarities, picture completion and digit symbol from the WAIS-R. The patients tested using the WAIS-R did not differ from those tested with the WAIS-III $[F(1,95)=0.98$, $p=0.325]$.

Executive function was measured using the Cambridge Automated Neuropsychological Test Battery (CANTAB; Sahakian \& Owen, 1992). Working memory spatial span (Owen et al. 1990) was measured by the ability to remember the order of sequences of squares presented on the screen in increasing number. Spatial working memory manipulation (Owen et al. 1990) was measured by the number of errors made on a task in which subjects 'opened' sets of boxes, varying between three and eight in number, to find tokens. Planning (Owen et al. 1990) was measured on a task where subjects moved coloured 'balls' in an arrangement on the screen to match a goal arrangement in problems differing in difficulty; accuracy was measured as the number of perfect solutions. Attentional set-shifting (Owen et al. 1991) was measured in a task where subjects learned a series of visual discriminations in which one of two stimulus dimensions was relevant. On the penultimate extra-dimensional shift (EDS) stage, the rule was reversed so that a previously irrelevant dimension now became relevant. Number of errors at this stage assessed the ability to inhibit the previously correct response set by shifting attention from one dimension to another.

Verbal memory was measured with the Rey Auditory Verbal Learning Task (RAVLT; Lezak, 1995). In trials $1-5$, subjects were read the same list of 15 nouns and asked to recall as many as possible immediately afterwards. In trial 6 , a second list was read and recalled. In trial 7 (short-delay), the original list was recalled without the list being read. After 25-30 min had elapsed, filled with performance of the executive tasks, the participants were asked to recall the original list again without the list being read (longdelay, trial 8). Trial 9 was a recognition memory trial. Extracted variables were: immediate memory (trial 1 recall), total number of words recalled during learning over trials 1-5 (learning), short-delay free recall (trial 7), long-delay free recall (trial 8) and recognition (trial 9 hit rate and false alarms rate). d prime was calculated using the hit and false alarm rates from the recognition trial $[z$ (hit rate) $-z$ (false alarm rate) $]$ to provide an index of the subjects' ability to detect 
correct words while accounting for any bias in responding. We also calculated a savings score for memory retention as the percentage of items recalled on long-delay trial 8 as a function of the score on shortdelay trial 7. A savings measure allows retention to be assessed more independently of performance over the learning trials than a simple delayed recall trial score (Seidman et al. 1998). Two interference measures were calculated: proactive interference (the degree to which old material impairs the acquisition of new material, measured as trial 6 less trial 1) and retroactive interference (the degree to which new material impedes the retrieval of previously learned material, measured as trial 5 less trial 7).

\section{Analyses}

Data were analysed using SPSS version 15 (SPSS Inc., Chicago, IL, USA) and Mplus 4 (Muthén \& Muthén, USA). ANOVA or ANCOVA was used for group comparisons. Categorical data were analysed using $\chi^{2}$. Separately for each group, the scores were $z$ transformed to standardize scaling. Pearson's $r$ correlations were performed to determine relationships between measures. An exploratory factor analysis (EFA) using unweighted least squares was performed to determine the best factor structure, with orthogonal rotation and loadings over 0.25 being retained. Both factor structures were then tested in the group from which they had been produced and the other group using confirmatory factor analyses (CFA).

\section{Results}

Table 1 shows that the matching procedure resulted in there being no significant differences in age, sex or premorbid IQ between the groups. Current WAIS IQ was significantly different between the groups; all executive and memory measures, with the exception of proactive interference, were also different. Z-score transformations of raw data, calculated in relation to the mean and standard deviation of the control, were performed for each trial of the auditory verbal learning test and are shown in Fig. 1. This demonstrates the extent to which the patients underperformed on verbal learning and memory compared to the matched controls.

To examine the effect of learning capacity on free recall, we compared the two groups on short-delay free recall (trial 7) while covarying for learning (sum trials 1-5) using ANCOVA. This showed that, despite learning being a highly significant covariate $[F(1,191)=191.13, p<0.001]$, the difference between the groups remained significant once this was accounted for $[F(1,191)=8.38, p=0.004]$. We repeated this analysis on long-delay free recall (trial 8) and,

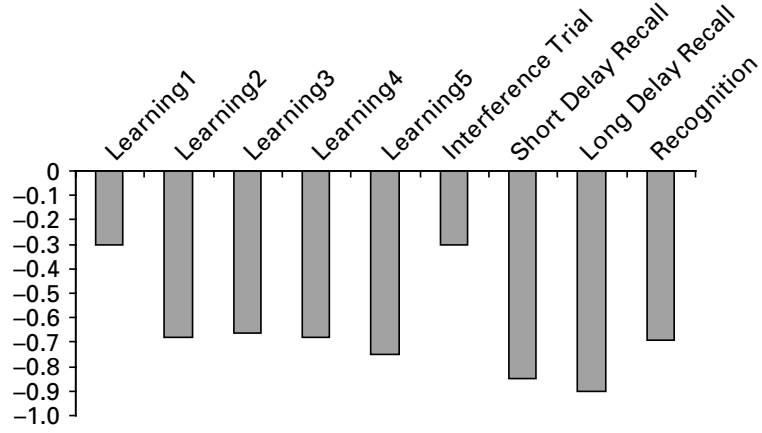

Fig. 1. Mean patient performance on each stage of the auditory verbal learning task, shown as $z$ scores transformed to the control data.

again, learning was a highly significant covariate $[F(1,191)=164.53, p<0.001]$ and the difference between the groups remained significant $[F(1,191)=$ 13.466, $p<0.001]$. Examining long-delay free recall with both learning and short-delay free recall as covariates showed learning $[F(1,190)=12.29, p=0.001]$ and short-delay recall $[F(1,190)=143,85, p<0.001]$ to be significant covariates and that the difference between the groups for long-delay free recall remained significant $[F(1,190)=5.24, p=0.023]$. When we examined the effect of learning on recognition memory, learning was a significant covariate as before $[F(1,191)=98.75, p<0.001]$ and the difference between groups in recognition score was no longer significant with this accounted for $[F(1,191)=1.57, p=0.212]$.

To examine the relationship between verbal learning and memory and other cognitive functions, correlations between measures were determined for each group (see Table 2). Factor analyses were performed using the $z$-score transformations of current IQ, verbal learning, verbal memory retention, working memory span, working memory manipulation, planning and attentional set-shifting.

\section{Factor analyses}

EFA revealed that a three-factor model was most appropriate in the control group (see Table 3 for factor loading pattern and eigenvalues). CFA of this model in the control group showed that it was a good fit $\left[\chi^{2}=10.38, \mathrm{df}=8, p=0.239\right.$, Comparative Fit Index $(\mathrm{CFI})=0.978$, Bayesian Information Criterion $(\mathrm{BIC})=$ 1924.98, root mean square error of approximation $($ RMSEA $)=0.055,90 \%$ confidence interval $(C I) 0.00$ 0.139] although current IQ loaded negatively on the first factor. Therefore, other models were tested, including simple structure models (where measures that loaded onto more than one factor were only assigned to the factor onto which they loaded the most) and models with current IQ allowed to load onto the first 
Table 2. Pearson's $r$ correlation matrix of cognitive measures in $(a)$ controls and $(b)$ patients

\begin{tabular}{|c|c|c|c|c|c|c|}
\hline & IQ & $\begin{array}{l}\text { Verbal } \\
\text { learning }\end{array}$ & $\begin{array}{l}\text { Verbal } \\
\text { memory } \\
\text { retention }\end{array}$ & $\begin{array}{l}\text { Attentional } \\
\text { set-shifting }\end{array}$ & Planning & $\begin{array}{l}\text { Spatial } \\
\text { working } \\
\text { memory } \\
\text { errors }^{\mathrm{a}}\end{array}$ \\
\hline \multicolumn{7}{|l|}{ (a) Controls } \\
\hline Verbal learning & $0.39^{* * *}$ & & & & & \\
\hline Verbal memory retention & 0.01 & $0.34^{* * *}$ & & & & \\
\hline Attentional set-shifting ${ }^{\mathrm{a}}$ & $0.38^{* * *}$ & 0.16 & 0.07 & & & \\
\hline Planning & $0.35^{* * *}$ & $0.35^{* * *}$ & $0.20^{\#}$ & 0.05 & & \\
\hline Spatial working memory errors ${ }^{a}$ & $0.45^{* * *}$ & $0.30^{* *}$ & -0.04 & $0.26^{* *}$ & $0.46^{* * *}$ & \\
\hline Spatial span & $0.22^{* * *}$ & 0.17 & -0.01 & $0.25^{*}$ & $0.27^{* *}$ & $0.40^{* * *}$ \\
\hline \multicolumn{7}{|l|}{ (b) Patients } \\
\hline Verbal learning & $0.50^{* * *}$ & & & & & \\
\hline Verbal memory retention & 0.15 & 0.13 & & & & \\
\hline Attentional set-shifting ${ }^{\mathrm{a}}$ & $0.37^{* * *}$ & $0.25^{*}$ & -0.10 & & & \\
\hline Planning & $0.47^{* * *}$ & $0.29^{* *}$ & 0.17 & $0.29^{* *}$ & & \\
\hline Spatial working memory errors $\mathrm{a}^{\mathrm{a}}$ & $0.45^{* * *}$ & $0.43^{* * *}$ & 0.02 & $0.40^{* * *}$ & $0.40^{* * *}$ & \\
\hline Spatial span & $0.55^{* * *}$ & $0.38^{* * *}$ & -0.11 & $0.21^{\#}$ & $0.36^{* * *}$ & $0.55^{* * *}$ \\
\hline
\end{tabular}

WAIS, Wechsler Adult Intelligence Scale.

${ }^{a}$ Error scores have been inverted.

* Significant at $p<0.05,{ }^{* *}$ significant at $p<0.01, * * *$ significant at $p<0.001$.

Table 3. Orthogonal (Varimax) rotated factor loading patterns for the patient and control groups using exploratory factor analysis (unweighted least squares)

\begin{tabular}{lcccc}
\hline & \multicolumn{2}{l}{ Controls } & & \\
\cline { 2 - 3 } & $\begin{array}{l}\text { Working } \\
\text { memory and } \\
\text { planning }\end{array}$ & $\begin{array}{l}\text { Flexible } \\
\text { thinking }\end{array}$ & $\begin{array}{c}\text { Episodic } \\
\text { memory }\end{array}$ & $\begin{array}{c}\text { Patients } \\
\text { General }\end{array}$ \\
\hline Eigenvalues & 2.55 & 1.24 & 0.96 & 3.00 \\
$\quad$ Percentage of variance explained & 24 & 24 & 12 & 35 \\
WAIS IQ & $\mathbf{0 . 5 5}$ & $\mathbf{0 . 2 7}$ & 0.14 & $\mathbf{0 . 7 9}$ \\
Verbal learning & $\mathbf{0 . 4 0}$ & 0.08 & $\mathbf{0 . 5 2}$ & $\mathbf{0 . 5 9}$ \\
Verbal memory retention & -0.05 & 0.02 & $\mathbf{0 . 6 8}$ & $0.08^{\mathrm{b}}$ \\
Attentional set-shifting & 0.20 & $\mathbf{0 . 9 8}$ & 0.06 & $\mathbf{0 . 4 6}$ \\
Planning & $\mathbf{0 . 5 9}$ & -0.08 & $\mathbf{0 . 2 9}$ & $\mathbf{0 . 5 7}$ \\
Spatial working memory errors & $\mathrm{a}$ & 0.11 & -0.02 & $\mathbf{0 . 7 1}$ \\
Spatial span & $\mathbf{0 . 8 0}$ & 0.15 & -0.01 & $\mathbf{0 . 6 7}$ \\
\hline
\end{tabular}

WAIS, Wechsler Adult Intelligence Scale.

Retained loadings over 0.25 are in bold face.

${ }^{a}$ Error scores have been inverted.

${ }^{\mathrm{b}}$ Removed for confirmatory factor analysis (CFA).

or second factor. The best model allowed current IQ to load onto the second factor only and this variation was retained $\left(\chi^{2}=10.58, \mathrm{df}=9, p=0.306, \mathrm{CFI}=0.985\right.$, $\mathrm{BIC}=1920.60, \mathrm{RMSEA}=0.043,90 \%$ CI $0.00-0.127$. The

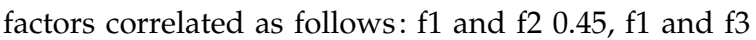
$0.06, \mathrm{f} 2$ and $\mathrm{f} 3 \mathrm{0.11}$ ). When the same three-factor model was tested on the patient group it was a poor fit $\left(\chi^{2}=18.35, \mathrm{df}=9, p=0.031, \mathrm{CFI}=0.94, \mathrm{BIC}=1879.48\right.$, RMSEA $=0.104,90 \%$ CI $0.030-0.171$. The factors correlated as follows: $\mathrm{f} 1$ and $\mathrm{f} 2 \mathrm{0.49}, \mathrm{f} 1$ and $\mathrm{f} 30.03, \mathrm{f} 2$ and f3 0.7). Unweighted least squares factor analysis of the patient group revealed that a one-factor model was the most appropriate although verbal memory retention did not load onto this factor (see Table 3 for 
factor loading pattern and eigenvalues). CFA of this model with verbal memory retention omitted in the patient group showed a good fit $\left(\chi^{2}=13.40, \mathrm{df}=9\right.$, $p=0.145, \mathrm{CFI}=0.970, \mathrm{BIC}=1578.43, \mathrm{RMSEA}=0.071$, $90 \%$ CI $0.00-0.145)$. In the control group the model was a reasonably good fit but less so than the threefactor model $\left(\chi^{2}=15.75, \mathrm{df}=9, p=0.072, \mathrm{CFI}=0.928\right.$, $\mathrm{BIC}=1634.49$, RMSEA $=0.088,90 \%$ CI 0.00-0.158).

Given the results of the previous analyses, to examine the degree to which verbal memory retention could predict group membership, we used data from both groups in a logistic regression with group membership (patient, control) as the binary dependent variable. Current IQ, verbal learning, working memory span, working memory manipulation, planning and attentional set-shifting were entered in a first block as predictors. This block was highly significant $\left(\chi^{2}=51.50, p<0.001, \mathrm{df}=6\right)$. Verbal memory retention was added in a second block and predicted a significant amount of the remaining variance $\left(\chi^{2}=3.90\right.$, $p=0.048, \mathrm{df}=1$ ).

Finally, we examined the relationship between verbal memory and clinical factors that might explain impaired verbal memory in the patient group (Paulsen et al. 1995): syndrome scores, depression, DUP, age at onset, and pre-morbid function where available (PSA and PSST). No correlations were significant with Bonferroni correction (range of $r^{\prime} s-0.02$ to 0.16 ). There were no differences between groups taking first- or second-generation medication (range of $t^{\prime} \mathrm{s}$ $0.01-1.41$ ) or between groups taking anticholinergic medication or not (range of $t^{\prime}$ s $0.12-0.62$ ).

\section{Discussion}

In this study, patients with schizophrenia were impaired, relative to pre-morbid IQ-, sex- and agematched healthy controls, at all stages of a verbal list learning task assessing immediate recall, learning, short- and long-delay free recall, and recognition. Studies of schizophrenia have frequently reported verbal memory deficits using list learning tasks and the deficits observed in this study are commensurate with the majority of these (see Cirillo \& Seidman, 2003). Deconstructing the relative contribution of encoding, retrieval and retention to the verbal memory deficit is difficult given their interdependence. Patients show defective strategic processes at encoding, for example by failing to spontaneously organize the to-be-remembered material (e.g. BonnerJackson et al. 2008) and their recall improves when given organizational strategies (Ragland et al. 2005). Furthermore, schizophrenia patients do not demonstrate greater facilitation when retrieval cues are presented (Brebion et al. 1997). These findings have been taken as evidence that underperformance during learning is due to encoding deficits (Cirillo \& Seidman, 2003) and our finding of poor recall on the first trial and impaired learning over subsequent trials supports this. Failure to adopt strategic encoding when learning word lists would also explain our finding of significantly greater retroactive interference effect on free recall of the initial list following presentation of a distractor word list (Craik, 2002; Blumenfeld \& Ranganath, 2007).

However, encoding difficulties do not entirely explain the poor performance of the patients later in the task. When we controlled for learning, patients were still significantly worse than controls on the short-delay recall trial; when we controlled for both learning and short-delay recall, there remained a significant difference between the groups on long-delay recall. Furthermore, the memory retention measure, which assessed savings during the 30-min interval between short- and long-delay recall trials revealed that patients retained fewer words over the long delay. This supports the notion of faster forgetting in this group and is in keeping with several other studies (Toulopoulou et al. 2003; Nuyen et al. 2005; Chan et al. 2006; Rametti et al. 2007). Thus, our findings support the conclusion of a comprehensive review (Cirillo \& Seidman, 2003), that there is 'mild but significantly impaired' retention in schizophrenia. Overall, the results suggest that there are both encoding and retention difficulties in patients with schizophrenia at illness onset.

Our finding that long-delay recognition but not recall memory was intact in patients once the influence of learning was accounted for might seem problematic for this conclusion as it suggests that the learned verbal material was available for recall, thus implicating a retrieval deficit. The majority of previous studies comparing free recall and recognition in schizophrenia also find intact or relatively preserved verbal recognition memory (Aleman et al. 1999; Cirillo \& Seidman, 2003). One issue here is that the RAVLT, similar to other list learning tests, requires respondents to recall the same words presented for recognition. Recognition performance is likely to be influenced by prior recall and this may have explained why recognition was no longer significantly different between groups once recall trial performance was accounted for. Nevertheless, the same influence of previous recall trials would be expected to impact on delayed recall and this remained different between groups.

Recognition is not as dependent on the integrity of the memory trace as free recall. Recent evidence suggests that recognition reflects two independent processes: recollection (as in free recall) and familiarity (Aggleton \& Brown, 2006). There is growing 
evidence that familiarity judgements are intact in schizophrenia and that, in the presence of impaired recollection, recognition memory is reliant on familiarity judgements (van Erp et al. 2008a,b). Thus, impaired free recall and intact recognition does not necessarily imply an explanation solely in terms of deficient retrieval processes.

Kirwan et al. (2008) report that activity in the MTL predicts memory strength whereas prefrontal cortex activity predicts recollection. Recollection may be impaired in contrast to familiarity because it is reliant on the prefrontal cortex, presenting as impaired recall but not recognition. However, correlation matrices of the neuropsychological measures used in this study revealed that verbal memory retention was not significantly correlated with several executive measures, suggesting that it is relatively independent.

To further understand the relationships between memory, executive function and general ability, we performed a factor analysis on current IQ, verbal learning and memory and measures of working memory span and manipulation, planning and attentional set-shifting. In the controls, three factors were produced corresponding to spatial working memory/ planning, set-shifting and episodic memory. Separation by factor analysis of CANTAB measures of attentional set-shifting on the one hand and spatial span, spatial working memory and planning on the other has previously been found in a study of healthy ageing, which also showed that these two factors were distinct from a third factor containing measures of episodic memory (Robbins et al. 1998). Thus, the factor structure we obtained for controls seems consistent. The observation that IQ loaded primarily on the factors of working memory and flexible thinking is in keeping with the high degree of correlation between general ability and these executive functions in normal populations (see Blair, 2006).

The patients showed a different pattern on factor analysis of the same variables in that all variables, except verbal memory retention, loaded onto a single factor. Verbal memory retention was completely uncorrelated with the other measures in this group. This suggests that, in patients with schizophrenia, verbal learning but not memory retention is highly related to executive function and supports the view that prefrontal cortex dysfunction is significantly associated with episodic memory encoding and probably underpins the learning deficits in schizophrenia (Fletcher \& Henson, 2001). Verbal memory retention, being independent of this relationship, may be a better index of MTL function (Alvarez \& Squire, 1994).

A second interpretation of the factor analysis findings is that cognitive function in schizophrenia is more generalized than normal. Whereas there were three factors explaining cognitive function in controls, the variance in the patient group could not be explained by this model. Rather, it fitted a model with a single factor representing IQ, working memory, planning, set-shifting and verbal learning. This finding is in agreement with large studies of first-episode (Keefe et al. 2004; Addington et al. 2005) and established schizophrenia (Keefe et al. 2006), which found that all cognitive scores loaded on a single factor. Dickinson et al. (2006), in a factor analysis study, also found that more of the variance in observed cognitive performance was determined by generalized cognitive ability in schizophrenia compared to healthy controls.

As verbal memory retention emerged as an independent measure in the patient group, we examined whether two dimensions of cognitive impairment, generalized deficit and impaired verbal memory retention, could independently distinguish patients and controls. In a logistic model predicting group, we found that when all variables contributing to the general factor were entered in a single block, this was a strong predictor of group membership, but when the verbal memory retention score was entered subsequently, this was still able to significantly predict group membership. Thus, the variation in verbal memory retention scores that distinguished the patients and controls seemed to be independent of the variation in the other test scores. This supports the view that this is an independent deficit. A recent factor analysis study (Dickinson et al. 2008) is consistent with our findings. This examined the factor structure of cognition in patients with schizophrenia and healthy controls and, although there was a generalized cognitive deficit across all domains in the patient group, there remained direct effects of diagnosis on verbal memory and processing speed. The authors concluded that these aspects of neurocognitive functioning may be 'more specifically implicated in schizophrenia than other cognitive domains'.

Our finding supports the view that IQ and executive impairments in schizophrenia reflect a common abnormality of information processing rather than a collection of specific impairments (Dickinson et al. 2007) and that this includes verbal learning but not verbal memory retention. In turn, this implies that many different forms of cognitive impairment share the same abnormal neural underpinnings and/or aetiological factors. Verbal memory retention, being different in this respect, may have a more distinct aetiology, such as increased vulnerability to environmental influences. There is some support for this conjecture. A recent study examined performance on the Weschler Logical Memory Scale in schizophrenia patients, sibling and controls (Skelley et al. 2008) and found that, whereas both patients and siblings were 
impaired on immediate and 30-min delayed recall, only patients demonstrated attenuated savings scores.

Epidemiological evidence suggests that poor verbal memory is associated with an earlier age of onset of psychosis, independent of a family loading of psychosis (Tuulio-Henriksson et al. 2004), indicating that verbal memory impairment might reflect an environmentally mediated risk factor for an earlier onset (see Joyce, 2005). Structural magnetic resonance imaging (MRI) studies of schizophrenia find that the most striking and consistent brain volume reductions are in the left MTL (Wright et al. 2000; Honea et al. 2005). This observation may be relevant to the finding that foetal hypoxia, known to have a neurotoxic effect on the hippocampus, is also a risk factor for an earlier onset of psychosis (Cannon et al. 2000; Rosso et al. 2000). Finally of interest is the syndrome of 'developmental amnesia', which occurs following a hypoxic insult at birth or in early childhood and is characterized by isolated hippocampal pathology, impaired episodic memory and relatively preserved recognition memory and judgement of familiarity (Vargha-Khadem et al. 2001). Although the delayed recall deficit is much more severe in this disorder than in schizophrenia, it has a similar pattern of verbal memory impairment and illustrates how an environmental insult in early life can be associated with specific verbal memory impairments later in life, and thus may be a partial model of one aspect of the cognitive impairment in schizophrenia.

\section{Acknowledgements}

This study was funded by a programme grant from the Wellcome Trust (number 064607). E.M.J. is supported by The Raymond Way Fund. We are grateful to the consultants and nurses of West London and South West London and St George's Mental Health National Health Service (NHS) Trusts for greatly facilitating the study.

\section{Declaration of Interest}

T.R.E.B. has acted as a consultant for Servier, Johnson \& Johnson and Bristol-Myers Squibb in the past 3 years. T.W.R. is a consultant for Cambridge Cognition.

\section{References}

Addington J, Saeedi H, Addington D (2005). The course of cognitive functioning in first episode psychosis: changes over time and impact on outcome. Schizophrenia Research 78, 35-43.

Aggleton JP, Brown MW (2006). Interleaving brain systems for episodic and recognition memory. Trends in Cognitive Sciences 10, 455-463.
Aleman A, Hijman R, de Haan EHF, Kahn RS (1999). Memory impairment in schizophrenia: a meta-analysis. American Journal of Psychiatry 156, 1358-1366.

Alvarez P, Squire LR (1994). Memory consolidation and the medial temporal lobe: a simple network model. Proceedings of the National Academy of Sciences USA 91, 7041-7045.

Andreasen N (1983). The Scale for the Assessment of Negative Symptoms (SANS). University of Iowa: Iowa City.

Andreasen N (1984). The Scale for the Assessment of Positive Symptoms (SAPS). University of Iowa: Iowa City.

Barnes TRE, Hutton SB, Chapman MJ, Mutsatsa SH, Puri BK, Joyce EM (2000). West London first-episode study of schizophrenia: clinical correlates of duration of untreated psychosis. British Journal of Psychiatry 177, 207-211.

Bilder RM, Goldman RS, Robinson D, Reiter G, Bell L, Bates JA, Pappadolulos E, Wallson DF, Alvir JM, Woerner MG, Geisler S, Kane JM, Lieberman JA (2000). Neuropsychology of first-episode schizophrenia: initial characterization and clinical correlates. American Journal of Psychiatry 157, 549-559.

Blair C (2006). How similar are fluid cognition and general intelligence? A developmental neuroscience perspective on fluid cognition as an aspect of human cognitive ability. Behaviour and Brain Science 29, 109-125.

Blumenfeld RS, Ranganath C (2007). Prefrontal cortex and long-term memory encoding: an integrative review of findings from neuropsychology and neuroimaging. The Neuroscientist 13, 280-291.

Blyler CR, Gold JM, Iannone VN, Buchanan RW (2000). Short form of the WAIS-III for use with patients with schizophrenia. Schizophrenia Research 46, 209-215.

Bonner-Jackson A, Yodkovik N, Csernansky JG, Barch DM (2008). Episodic memory in schizophrenia: The influence of strategy use on behavior and brain activation. Psychiatry Research: Neuroimaging 164, 1-15.

Brebion G, Amador X, Smith MJ, Gorman JM (1997). Mechanisms underlying memory impairment in schizophrenia. Psychological Medicine 27, 383-393.

Cannon TD, Rosso IM, Hollister JM, Bearden CE, Sanchez LE, Hadley T (2000). A prospective cohort study of genetic and perinatal influences in the etiology of schizophrenia. Schizophrenia Bulletin 26, 351-366.

Chan RCK, Chen EYH, Law CW (2006). Specific executive dysfunction in patients with first-episode medication-naive schizophrenia. Schizophrenia Research 82, 51-64.

Cirillo MA, Seidman LJ (2003). Verbal declarative memory dysfunction in schizophrenia: from clinical assessment to genetics and brain mechanisms. Neuropsychology Review 13, 43-77.

Craik FIM (2002). Levels of processing : past, present ... and future? Memory 10, 305-318.

Dickinson D, Iannone VN, Wilk CM, Gold JM (2004). General and specific cognitive deficits in schizophrenia. Biological Psychiatry 55, 826-833.

Dickinson D, Ragland JD, Calkins ME, Gold JM, Gur RC (2006). A comparison of cognitive structure in schizophrenia patients and healthy controls using 
confirmatory factor analysis. Schizophrenia Research 85, 20-29.

Dickinson D, Ragland JD, Gold JM, Gur RC (2008). General and specific cognitive deficits in schizophrenia: Goliath defeats David? Biological Psychiatry 64, 823-827.

Dickinson D, Ramsey ME, Gold JM (2007). Overlooking the obvious: a meta-analytic comparison of digit symbol coding tasks and other cognitive measures in schizophrenia. Archives of General Psychiatry 64, 532-542.

Fletcher PC, Henson RNA (2001). Frontal lobes and human memory: insights from functional neuroimaging. Brain 124, 849-881.

Foerster A, Lewis S, Owen M, Murray RM (1991). Pre-morbid adjustment and personality in psychosis: effects of sex and diagnosis. British Journal of Psychiatry 158, 171-176.

Green MF, Kern RS, Braff DL, Mintz J (2000). Neurocognitive deficits and functional outcome in schizophrenia: are we measuring the 'right stuff'? Schizophrenia Bulletin 26, 119-136.

Hamilton M (1960). A rating scale for depression. Journal of Neurology, Neurosurgery and Psychiatry 23, 56-62.

Heinrichs RW, Zakzanis KK (1998). Neurocognitive deficit in schizophrenia: a quantitative review of the evidence. Neuropsychology 12, 426-445.

Holthausen EA, Wiersma D, Sitskoorn MM, Dingemans PM, Schene AH, Van den Bosch RJ (2003). Long-term memory deficits in schizophrenia: primary or secondary dysfunction? Neuropsychology 17, 539-547.

Honea R, Crow TJ, Passingham D, Mackay CE (2005). Regional deficits in brain volume in schizophrenia: a meta-analysis of voxel-based morphometry studies. American Journal of Psychiatry 162, 2233-2245.

Joyce EM (2005). Origins of cognitive dysfunction in schizophrenia: clues from age at onset. British Journal of Psychiatry 186, 93-95.

Joyce EM, Hutton SB, Mutsatsa SH, Barnes TRE (2005). Cognitive heterogeneity in first-episode schizophrenia. British Journal of Psychiatry 187, 516-522.

Keefe RSE, Bilder RM, Harvey PD, Davis SM, Palmer BW, Gold JM, Meltzer HY, Green MF, Miller DD, Canive JM, Adler LW, Manschreck TC, Swartz M, Rosenheck R, Perkins DO, Walker TM, Stroup TS, McEvoy JP, Lieberman JA (2006). Baseline neurocognitive deficits in the CATIE schizophrenia trial. Neuropsychopharmacology 31, 2033-2046.

Keefe RSE, Seidman LJ, Christensen BK, Hamer RM, Sharma T, Sitskoorn MM, Lewine RRJ, Yurgelun-Todd DA, Gur RC, Tohen M, Tollefson GD, Sanger TM, Lieberman JA (2004). Comparative effect of atypical and conventional antipsychotic drugs on neurocognition in first-episode psychosis: a randomized, double-blind trial of olanzapine versus low doses of haloperidol. American Journal of Psychiatry 161, 985-995.

Kirwan CB, Wixted JT, Squire LR (2008). Activity in the medial temporal lobe predicts memory strength, whereas activity in the prefrontal cortex predicts recollection. Journal of Neuroscience 28, 10541-10548.
Kristian Hill S, Beers SR, Kmiec JA, Keshavan MS, Sweeney JA (2004). Impairment of verbal memory and learning in antipsychotic-naive patients with first-episode schizophrenia. Schizophrenia Research 68, 127-136.

Lee TMC, Chan MWC, Chan CCH, Gao J, Wang K, Chen EYH (2006). Prose memory deficits associated with schizophrenia. Schizophrenia Research 81, 199-209.

Lezak MD (1995). Neuropsychological Assessment, 3rd edn. Oxford University Press: New York.

Liddle PF, Barnes TRE (1990). Syndromes of chronic schizophrenia. British Journal of Psychiatry 157, 558-561.

Missar CD, Gold JM, Goldberg TE (1994). WAIS-R short forms in chronic schizophrenia. Schizophrenia Research 12, 247-250.

Mohamed S, Paulsen JS, O'Leary D, Arndt S, Andreasen N (1999). Generalized cognitive deficits in schizophrenia : a study of first-episode patients. Archives of General Psychiatry 56, 749-754.

Nelson HE, Willison JR (1991). The Revised National Adult Reading Test: Test Manual. NFER-Nelson: Windsor.

Nuechterlein KH, Barch DM, Gold JM, Goldberg TE, Green MF, Heaton RK (2004). Identification of separable cognitive factors in schizophrenia. Schizophrenia Research 72, 29-39.

Nuyen J, Sitskoorn MM, Cahn W, Kahn RS (2005). Verbal memory in first-episode schizophrenia: heterogeneity in performance? Journal of the International Neuropsychological Society 11, 152-162.

Owen AM, Downes JJ, Sahakian BJ, Polkey CE, Robbins TW (1990). Planning and spatial working memory following frontal lobe lesions in man. Neuropsychologia 28, 1021-1034.

Owen AM, Roberts AC, Polkey CE, Sahakian BJ, Robbins TW (1991). Extra-dimensional versus intra-dimensional set shifting performance following frontal lobe excisions, temporal lobe excisions or amygdalo-hippocampectomy in man. Neuropsychologia 29, 993-1006.

Paulsen JS, Heaton RK, Sadek JR, Perry W, Delis DC, Braff D, Kuck J, Zisook S, Jeste DV (1995). The nature of learning and memory impairments in schizophrenia. Journal of the International Neuropsychological Society 1, 88-99.

Ragland JD, Gur RC, Valdez JN, Loughead J, Elliott M, Kohler C, Kanes S, Siegel SJ, Moelter ST, Gur RE (2005). Levels-of-processing effect on frontotemporal function in schizophrenia during word encoding and recognition. American Journal of Psychiatry 162, 1840-1848.

Rametti G, Segarra N, Junque C, Bargallo N, Caldu X, Ibarretxe N, Bernardo M (2007). Left posterior hippocampal density reduction using VBM and stereological MRI procedures in schizophrenia. Schizophrenia Research 96, 62-71.

Ranganath C, Minzenberg MJ, Ragland JD (2008). The cognitive neuroscience of memory function and dysfunction in schizophrenia. Biological Psychiatry 64, $18-25$.

Robbins TW, James M, Owen AM, Sahakian BJ, Lawrence AD, McInnes L, Rabbitt PM (1998). A study of performance on tests from the CANTAB battery sensitive to frontal lobe dysfunction in a large sample 
of normal volunteers: implications for theories of executive functioning and cognitive aging. Journal of the International Neuropsychological Society 4, 474-490.

Roofeh D, Cottone J, Burdick KE, Lencz T, Gyato K, Cervellione KL, Napolitano B, Kester H, Anderson B, Kumra $S$ (2006). Deficits in memory strategy use are related to verbal memory impairments in adolescents with schizophrenia-spectrum disorders. Schizophrenia Research 85, 201-212.

Rosso IM, Cannon TD, Huttunen T, Huttunen MO, Lonnqvist J, Gasperoni TL (2000). Obstetric risk factors for early-onset schizophrenia in a Finnish birth cohort. American Journal of Psychiatry 157, 801-807.

Sahakian BJ, Owen AM (1992). Computerized assessment in neuropsychiatry using CANTAB: discussion paper. Journal of the Royal Society of Medicine 85, 399-402.

Saykin AJ, Shtasel DL, Gur RE, Kester DB, Mozley LH, Stafiniak P, Gur RC (1994). Neuropsychological deficits in neuroleptic naive patients with first-episode schizophrenia. Archives of General Psychiatry 51, 124-131.

Seidman LJ, Stone WS, Jones R, Harrison RH, Mirsky AF (1998). Comparative effects of schizophrenia and temporal lobe epilepsy on memory. Journal of the International Neuropsychological Society 4, 342-352.

Skelley SL, Goldberg TE, Egan MF, Weinberger DR, Gold JM (2008). Verbal and visual memory: characterizing the clinical and intermediate phenotype in schizophrenia. Schizophrenia Research 105, 78-85.

Toulopoulou T, Rabe-Hesketh S, King H, Murray RM, Morris RG (2003). Episodic memory in schizophrenic patients and their relatives. Schizophrenia Research 63, 261-271.

Tuulio-Henriksson A, Partonen T, Suvisaari J, Haukka J, Lonnqvist J (2004). Age at onset and cognitive functioning in schizophrenia. British Journal of Psychiatry 185, 215-219.

van Erp TGM, Lesh TA, Knowlton BJ, Bearden CE, Hardt M, Karlsgodt KH, Shirinyan D, Rao V, Green MF, Subotnik KL, Nuechterlein K, Cannon TD (2008a). Remember and know judgments during recognition in chronic schizophrenia. Schizophrenia Research 100, 181-190.

van Erp TGM, Therman S, Pirkola T, Tuulio-Henriksson A, Glahn DC, Bachman P, Huttunen MO, Lönnqvist J, Hietanen M, Kaprio J, Koskenvuo M, Cannon TD (2008b). Verbal recall and recognition in twins discordant for schizophrenia. Psychiatry Research 159, 271-280.

Vargha-Khadem F, Gadian DG, Mishkin M (2001). Dissociations in cognitive memory: the syndrome of developmental amnesia. Philosophical Transactions of the Royal Society of London, Series B: Biological Sciences 356, 1435-1440.

Wechsler D (1981). The Wechsler Adult Intelligence Scale Revised. The Psychological Corporation: New York.

Wechsler D (1997). Wechsler Adult Intelligence Scale, Third Edition (WAIS-3). Harcourt Assessment: San Antonio, TX. Wright IC, Rabe-Hesketh S, Woodruff PWR, David AS, Murray RM, Bullmore ET (2000). Meta-analysis of regional brain volumes in schizophrenia. American Journal of Psychiatry 157, 16-25. 